\title{
Análise da identidade cultural da cidade de Anastácio - MS: o contexto dos migrantes nordestinos
}

\section{Analysis of the cultural identity of the city of Anastácio, state of Mato Grosso do Sul (MS): the 'northeastern migrants' context}

Fernanda Kiyome Fatori Trevizan

Leonel Brizolla Monastirsky

Universidade Estadual de Ponta Grossa

Resumo: A população de Anastácio (MS) é composta por inúmeros migrantes, e, portanto, constitui-se em uma cidade culturalmente heterogênea que apresenta características específicas desses migrantes, mas também o resultado da aculturação entre as culturas exógenas e a local. O estudo propõe a análise da identidade cultural de Anastácio a partir da compreensão das manifestações culturais que fazem parte da construção da identidade cultural e também dos processos dialéticos entre o local e o global, bem como da dinâmica entre territórios e as transformações que as culturas apresentam na localidade.

Palavras-chave: Cultura. Identidade. Território. Anastácio/MS

Abstract: The population of the city of Anastácio, state of Mato Grosso do Sul (MS), is composed of many migrants, which results in a culturally diverse city that presents specific characteristics of these migrant populations. However, this also triggers a process of acculturation between the exogenous culture and the local culture. The present study proposes an analysis of the cultural identity of the city of Anastácio, based on the understanding of the cultural manifestations that are part of the construction of the cultural identity, as well as of the dialectical processes between local and global, the dynamics between the territories, and the changes that the analyzed cultures bring to the locality.

Keywords: Culture. Identity. Territory. Anastácio/MS 


\section{INTRODUÇÃO}

No início da colonização da região sudoeste do então Estado de Mato Grosso, os rios - entre eles o Aquidauana - se constitu1́am nas principais vias de transporte. Por volta de 1870, iniciou-se a ocupação das terras e povoamento da região. Em 1872, um italiano, Vicente Anastácio estabeleceu-se na região ao comprar uma propriedade, a Fazenda Santa Maria (CABRAL et al, 2003), onde posteriormente, nesta mesma propriedade, se estabeleceram as construções que são consideradas como os primeiros estabelecimentos comerciais, sendo que alguns são utilizados até hoje, como a Casa Cândia. No entanto, com o advento da estrada de ferro, mais precisamente em função dos trilhos que foram instalados na outra margem, o centro administrativo e populacional foi transferido para o outro lado do rio, originando assim o município de Aquidauana.

A partir da criação do núcleo populacional de Aquidauana, iniciouse o movimento para a emancipação de Anastácio, a princípio um bairro de Aquidauana e depois distrito, que passou a ser considerado município pela Lei $\mathrm{n}^{\circ} 2.143$, de 18 de março de 1964, da Assembleia Legislativa de Mato Grosso (S/A, 2009).

O município de Anastácio possui área de $2.954 .060 \mathrm{~km}^{2}$ (Figura 01), sendo que a maior parte é ocupada por propriedades rurais, e possui população aproximada de 23.012 habitantes de acordo com dados do IBGE de 2008. Sua área rural é constituída por propriedades particulares (sítios e fazendas) e três assentamentos (Monjolinho, Marcos Freire e São Manoel). Na área urbana, o município possui atividade comercial (supermercados, lojas de departamentos, lojas de atendimento ao produtor), e serviços básicos (centro médico e hospitalar, escolas do ensino fundamental e médio). Destaca-se na economia da cidade a presença de um frigorífico de grande porte que atende à pecuária bovina de corte atividade de destaque na composição do Produto Interno Bruto (PIB) do município (IBGE, 2007).

Figura 01 - Origem e descendência da população de Anastácio - MS

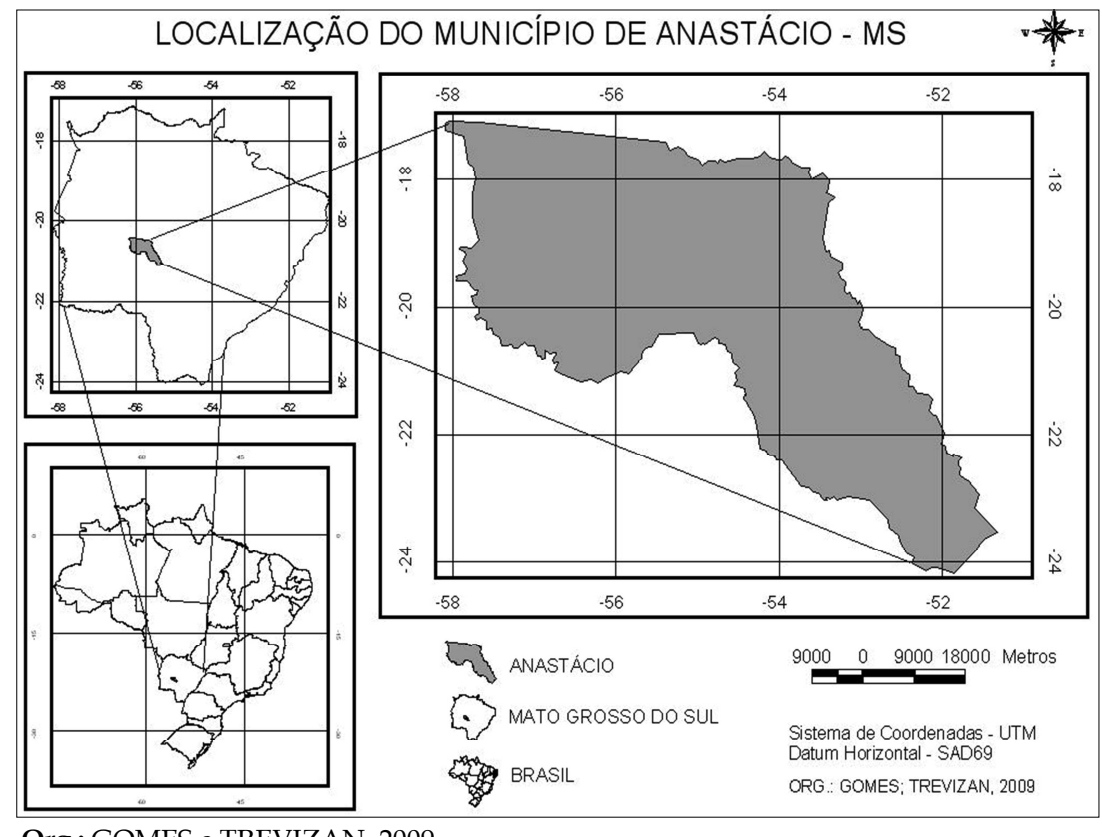

Org.: GOMES e TREVIZAN, 2009. 
A produção agrícola do município se restringe, na maioria dos casos, a produções de subsistência, principalmente nas áreas dos assentamentos, mas alguns produtos são vendidos no comércio local. Dentre os produtos cultivados, estão o milho, o arroz sequeiro, a banana, a laranja e a mandioca. A mandioca possui expressividade no comércio local através da venda do produto in natura e/ou seus derivados, como a farinha de mandioca e o polvilho (SILVA et al, 2005/2006).

A população do município é formada por uma miscigenação de povos, dentre os quais os imigrantes italianos, japoneses, paraguaios, bolivianos, alemães; e os migrantes de diversas regiões do Brasil - gaúchos, paulistas, mineiros e, principalmente, nordestinos.
Considerando que cada migrante possui características próprias de suas regiões de origem, o município recebeu diversas influências, que contribuem para a formação da identidade cultural de Anastácio. Acrescenta-se aos movimentos migratórios e de multiterritorialização, a dialética entre os territórios de origem dos fluxos migratórios e do município onde se estabeleceram.

Os migrantes nordestinos têm um papel importante na construção e formação de Anastácio, uma vez que eles foram pioneiros na região e, atualmente, se destacam nas manifestações culturais do município, especialmente na Festa da Farinha de Anastácio (Figuras 02 e 03). Trata-se de um evento de cunho gastronômico e cultural, onde a temática principal são as representações nordestinas.

Figura 02 - Pórtico da II Festa da Farinha de Anastácio - MS

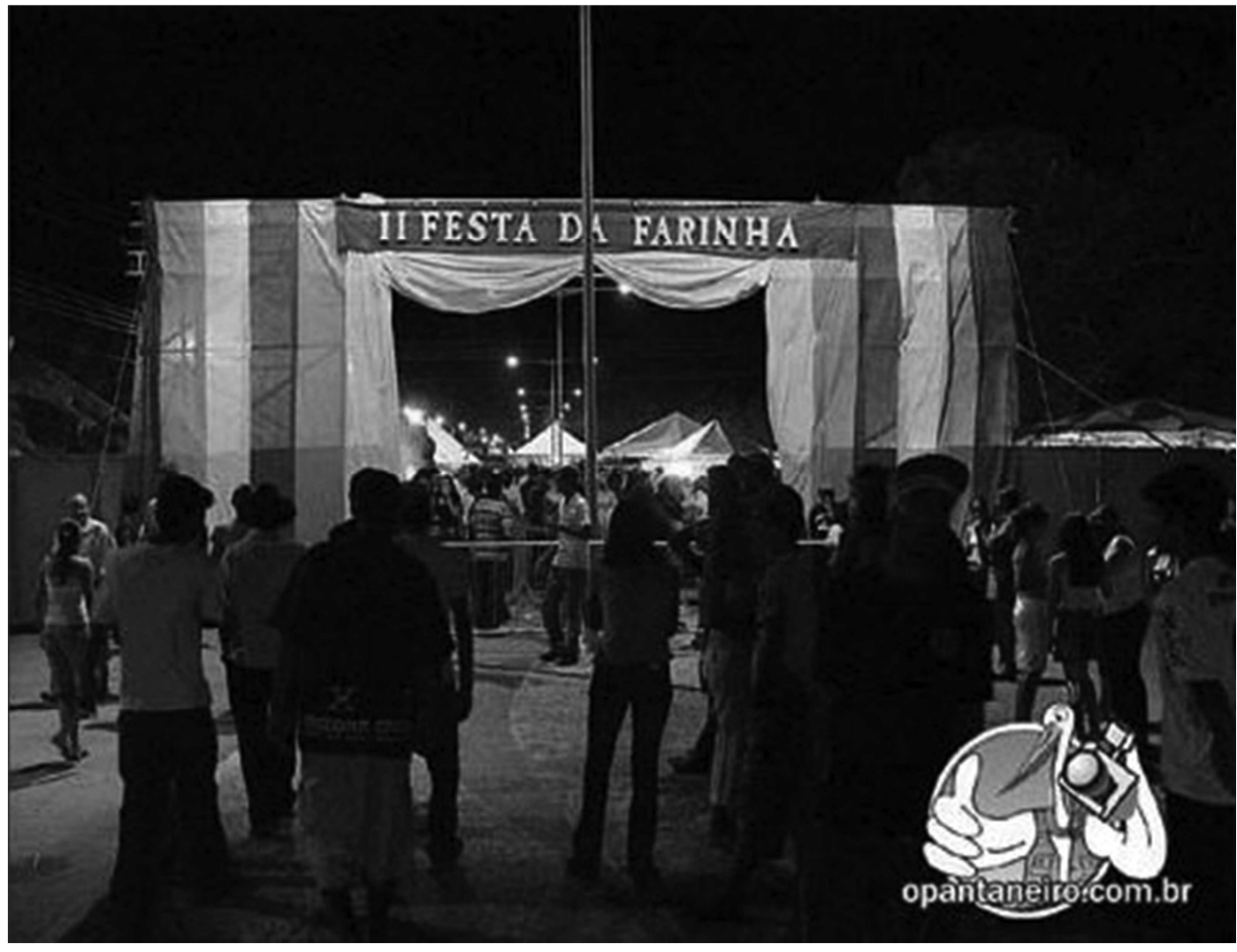

Fonte: Jornal O Pantaneiro, 2007 
Figura 03 - Casa de farinha - símbolo do evento

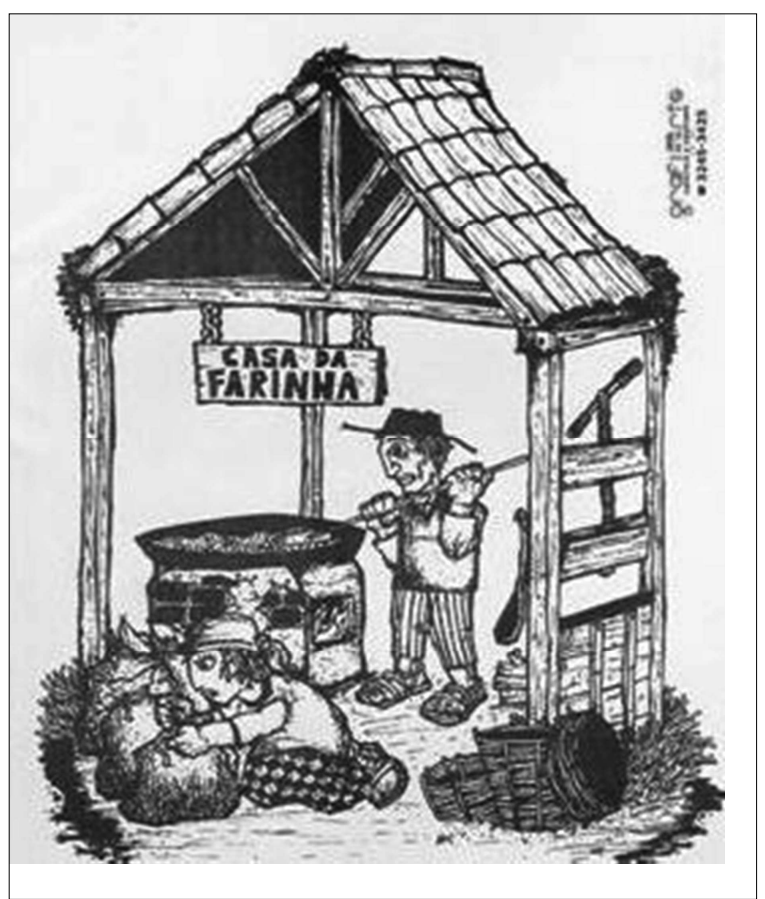

Fonte: LANZARINI, 2007.

O evento foi criado com o intuito de promover o município em âmbito estadual, gerar renda e desenvolvimento para a cidade e aos produtores de mandioca locais. Busca também divulgar a produção artesanal de farinha de mandioca proveniente dos assentamentos rurais locais, onde se concentram grande parte dos migrantes e descendentes nordestinos da localidade destaque para a Colônia Pulador. A colônia faz parte de um grupo de assentamentos localizados na área rural do município, onde inicialmente foi o local em que os migrantes nordestinos se fixaram ao chegar à região.

Desta forma, este estudo se propõe a analisar a identidade cultural de Anastácio a partir da compreensão das manifestações culturais que fazem parte da construção da identidade cultural e também dos processos dialéticos entre o local e o global, bem como da dinâmica entre territórios e as transformações que as culturas apresentam na localidade.

\section{CULTURA, IDENTIDADE CULTURAL E TERRITÓRIO}

As manifestações culturais que são originárias nas diferentes regiões do Brasil são percebidas em cada localidade que sofreu o processo de aculturação ao longo dos tempos. Essas trocas culturais são oriundas dos movimentos multiterritoriais, uma vez que as influências não se concentram apenas durante o seu processo de formação, mas através de um movimento constante, presente e contínuo nas dinâmicas de formação dos municípios.

A constituição das sociedades está diretamente relacionada à cultura que, por sua vez, está intimamente relacionada à identidade, visto que a cultura "[...] molda a identidade ao dar sentido à experiência e tornar possível optar, entre várias identidades possíveis por um modo especifico de subjetividade". Também podemos encarar a identidade como um sistema de significações que é produzido pelas representações que, por sua vez, da ênfase nestas. Assim, "[...] o papel-chave da cultura na produção dos significados permeia todas as relações sociais; levam, assim, a uma preocupação com a identificação" e com o que vem a ser considerado como a identidade cultural (WOODWARD, 2000, pp. 18-19). A identidade, por sua vez, pode ser compreendida como "[...] um significado - cultural e socialmente atribuído" aos indivíduos que vivem em uma determinada sociedade (SILVA, 2000, p. 89).

Considerando que a identidade cultural está diretamente relacionada com a sociedade que representa e também com a formação desta, nota-se que um fator de grande importância e influência para a identidade cultural está presente nas culturas que foram inseridas nas localidades. A identidade cultural, portanto, é composta pela união das culturas autóctones e dos povos migrantes, 
que inseriram as próprias culturas ao longo do processo de formação dos municípios e que passam a corresponder às representações culturais dos locais (OLIVEIRA, 2008).

Uma vez que a identidade cultural é caracterizada primeiramente em função das relações culturais que irão estabelecer-se nas localidades, torna-se primordial a compreensão das dinâmicas territoriais que irão se estabelecer, ou seja, a discussão de territórios e as territorialidades que estão (e são) inseridas neles.

O conceito de território pode ser considerado por várias áreas do conhecimento para descrever um espaço ocupado por um indivíduo, grupo ou o Estado, sendo que sua noção carrega em si, uma representação marcante. Trata-se da representação de um espaço apropriado política e simbolicamente, a qual se relaciona diretamente com a delimitação, a utilização, a distribuição e, sobretudo, a identificação do território (HAESBAERT, 2004).

A compreensão do território e de que forma se dá a sua formação está diretamente relacionada às suas territorialidades, visto que muitas vezes estas territorialidades correspondem a um conjunto de novas culturas e também acompanham os movimentos de deslocamento de pessoas, uma vez que os processos dialéticos também se apresentam durante todo o processo de formação contínua dos municípios, horizontalmente entre as regiões do Brasil e verticalmente entre as escalas global e local.

Assim, os processos dialéticos que se inserem nas localidades que apresentam movimentos migratórios em sua formação são compreendidos pela dinâmica dos territórios e a dialética das ordens local e global. A dinâmica dos territórios consiste nas formas em que a mesma cultura se apresenta em diferentes territórios, considerando os processos de influências a que esta estará sujeita - aculturação, relação de poder entre cultura dominante e cultura dominada, globalização. A análise desta dinâmica mostra as diferentes culturas que podem se originar desses processos.

As dialéticas da ordem local e da ordem global é caracterizada por Santos (2005, p.170) como "[...] duas situações geneticamente opostas ainda que em cada uma se verifiquem aspectos da outra":

A ordem global é desterritorializada, no sentido de que separa o centro da ação da sede da ação. Seu espaço é movediço e inconstante, é formado por pontos, cuja existência funcional é dependente de fatores externos. A ordem local, que reterritorializa, é a do espaço banal, espaço irredutível, porque reúne numa mesma lógica interna todos os seus elementos: homens, empresas, instituições, formas sociais e jurídicas, e formas geográficas. O cotidiano imediato, localmente vivido, traço de união de todos esses dados, é a garantia da comunicação (SANTOS, 2005, p.170).

O município de Anastácio não foge à lógica da formação da maioria dos municípios do Brasil, pois apresenta em sua sociedade os migrantes de diversas localidades do estado do Mato Grosso do Sul, do país e também a relação dialética entre o local e o global. Nas sociedades podemos encontrar diversos elementos da chamada "homogeneização cultural", em que está presente a tensão que se forma entre as esferas global e local, uma vez que o global tende a homogeneizar as identidades e o local surge como uma forma de resistência a essa homogeneização, fazendo com que algumas das características culturais locais se reforcem (ROCHA; MONASTIRSKY, 2008).

Desta forma, as cidades são compostas por inúmeras representações culturais e sociais, nas quais podem ser identificadas as características dos povos que recebem ao longo de sua formação. As cidades 
também são vistas como "lugares nodais do desenvolvimento da cultura", além de representarem uma característica especifica de serem consideradas como o local do "confronto entre culturas heterogéneas (sic)". Ou seja, historicamente falando, as cidades são consideradas como incubadoras de grandes transformações culturais - espaços onde as transformações sócio-culturais acontecem através de processos de "reorientação dos valores e comportamentos" de uma sociedade (MELA, 1999).

A formação da sociedade está diretamente relacionada com a cultura, que abrange os valores criados pela humanidade ao longo da construção de sua história (SODRÉ, 1996), ou seja, é vista como a soma das características encontradas em dada localidade, como sendo as representações e manifestações dessas características. Através dela são transmitidos e difundidos os conhecimentos, crenças, costumes e tradições de uma comunidade, pois a cultura está intrínseca aos seres humanos que vivem em sociedade, que são tidos como além de componentes das sociedades, também como agentes transformadores da cultura (CUCHE, 2002).

Anastácio possui uma população diversificada devido aos fluxos de migrantes que recebeu durante sua formação que, conseqüentemente, contribuíram não somente com o aumento significativo da sua população, mas também com a formação de sua cultura e identidade. Entre os povos exógenos a Anastácio, os migrantes nordestinos destacam-se não somente em quantidade, mas também em expressão cultural e social na cidade.

\section{IDENTIDADE CULTURAL DE ANASTÁCIO}

\subsection{Origem da População}

Durante o mês de Dezembro de 2009, foi realizada pesquisa de campo, em que foram entrevistados 115 moradores do município de Anastácio - os entrevistados foram abordados nas ruas da cidade, independente da região de origem e/ou descendência. Na continuidade da pesquisa foram selecionados para a entrevista qualitativa onze migrantes nordestinos. Através das entrevistas com os nordestinos e também com os seus descendentes foi possível caracterizar que os movimentos migratórios ocorreram em grupos de famílias que saíram, em sua maioria, do estado de Pernambuco e, principalmente, das cidades de Santa Maria do Cambucá e Vertentes para se instalarem em Colônias, no município de Anastácio.

Foram entrevistados onze migrantes nordestinos que residem na área urbana de Anastácio, com origem no estado de Pernambuco; também foram entrevistados dois migrantes do estado do Ceará. Este maior número de migrantes pernambucanos é refletido na cidade, pois uma expressão comum no local (e durante as entrevistas) é a de que "Anastácio só tem pernambucano"; no entanto, da mesma forma que os migrantes pernambucanos afirmaram terem se adaptado facilmente à região, o mesmo ocorreu aos migrantes cearenses. Um deles afirmou não ter se adaptado rapidamente, por se tratar de uma localidade diferente da qual estava habituado (Gráfico 01). 
Gráfico 01

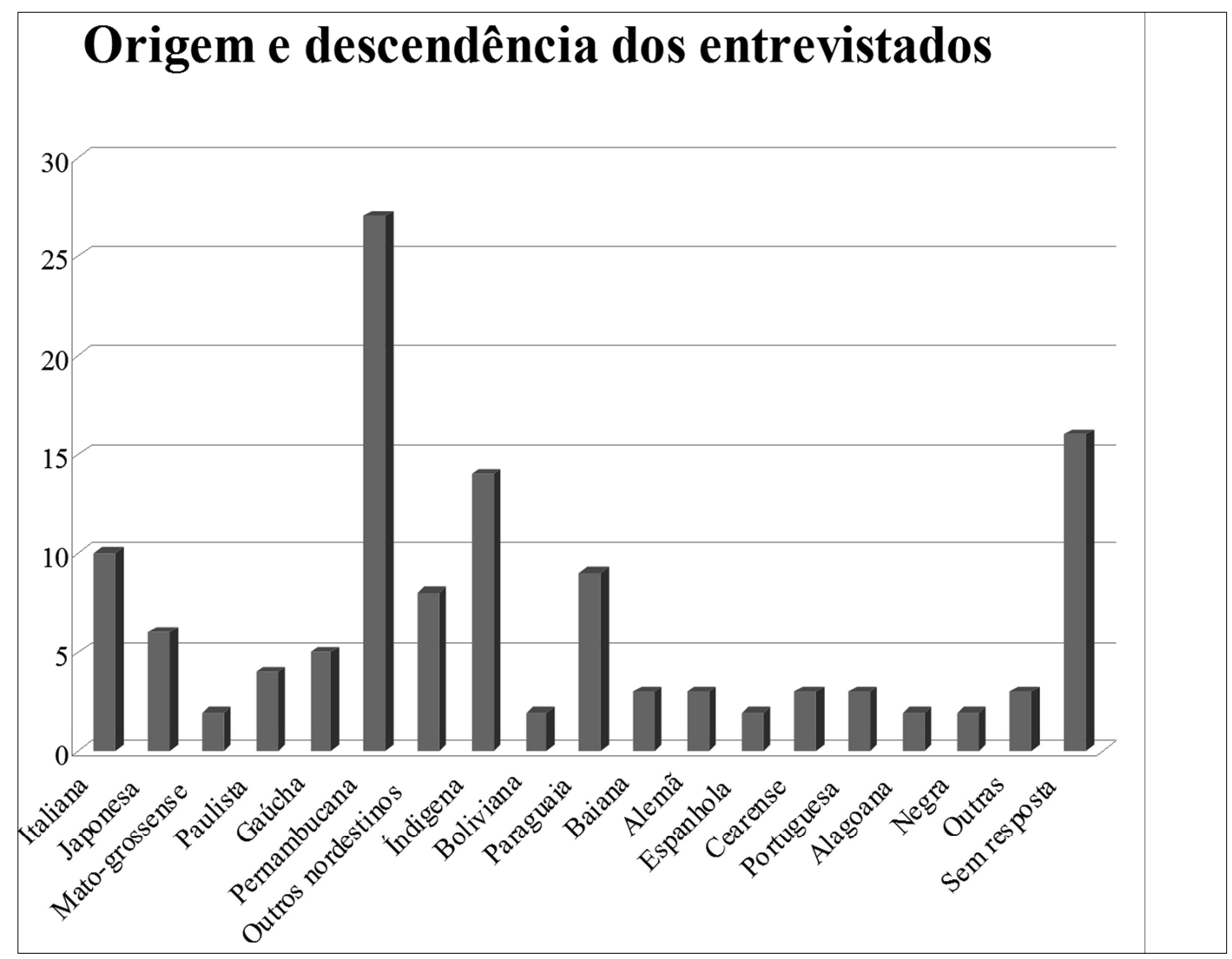

Fonte $^{1}$ : Pesquisa de campo, 2009.

Org.: TREVIZAN, 2010.

Conforme os dados apresentados no Gráfico 01, é possível constatar que Anastácio tem em sua população uma variedade bastante acentuada de migrantes e/ ou descendentes de migrantes, com destaque para os pernambucanos, confirmando o que foi dito pelos entrevistados, "que em Anastácio podem ser encontrados muitos pernambucanos". A presença de nordestinos no município pode ser observada também no poder público local, sendo que na administração municipal, das nove secretarias, cinco

\footnotetext{
${ }^{1}$ No Gráfico 01 não estão sendo representados aqueles que disseram ser anastacianos e os migrantes nordestinos, somente os entrevistados que afirmaram ter descendências de outras de outras regiões ou países. A opção "sem resposta" representa aqueles que não souberam dizer se possuem alguma descendência ou afirmam não tê-la(s). A parcela dos entrevistados que disseram ser descendentes de "outros nordestinos" está assim, pois, os entrevistados apenas afirmaram ser descendentes de nordestinos, sem especificar o Estado de origem da descendência.
}

delas são administradas por nordestinos ou descendentes; e no setor da educação pública, as três maiores escolas estaduais têm diretores com descendência nordestina (BARBOSA, 2009).

A população de Anastácio percebe a presença de migrantes nordestinos no município, comenta e demonstra que ocorreu a aceitação dos mesmos na cidade e, conseqüentemente, na sociedade anastaciana. Um número significativo de entrevistados não migrantes afirmaram que os migrantes nordestinos são "pessoas boas" e "pessoas trabalhadoras". Também pode-se observar que os anastacianos reconhecem a importância dos migrantes no município, uma vez que afirmam "são importantes para a cidade" e também que os migrantes formam a raiz do município, através da sua participação durante o processo inicial de criação da cidade. 
A presença cultural nordestina é facilmente notada no município, pois aproximadamente $80 \%$ dos entrevistados afirmaram conhecer algum hábito cultural nordestino. Dentre as características culturais mais conhecidas estão aquelas relacionadas à gastronomia, seguidas pela opção relacionada ás músicas. Esses indicativos podem ser motivados pelo evento "Festa da Farinha de Anastácio", que também aparece como uma característica cultural nordestina apontada com destaque pelos entrevistados. O evento é de cunho cultural e apresenta entre os seus principais atrativos exatamente a gastronomia e a música nordestinas. No entanto, a presença da cultura nordestina não se resume apenas a estes aspectos, mas também a outros hábitos e costumes cotidianos das pessoas que residem na cidade, uma vez que foi notada a presença de descendentes ou migrantes nordestinos em diferentes bairros de Anastácio.

Nesse momento devemos compreender a cultura como sendo um fator de diferenciação das populações ou das pessoas presentes em uma mesma localidade, que nos remete aos modos de vida e de pensamento, compreendendo a cultura como formas de manifestações que devem ser encaradas de acordo com o período e a sociedade em que estão sendo analisadas (CUCHE, 2002).

Desta forma, em Anastácio, a presença cultural nordestina se destaca mais expressivamente a partir do ano de 2006, com a realização da Festa da Farinha. Este evento garante visibilidade à cultura nordestina na cidade, através da divulgação da gastronomia, da vida cotidiana, da maneira de fazer as coisas, da música, da literatura, da linguagem, entre outros.

Os hábitos alimentares nordestinos também podem ser observados entre os habitantes que não possuem ligação sanguínea com os nordestinos. Quando perguntados quais hábitos culturais nordestinos praticam, a opção relacionada com a gastronomia destacou-se das demais, o que indica que alguns hábitos e receitas culinárias foram adquiridos através dos tempos e com a convivência com os nordestinos residentes na cidade.

Outro elemento cultural bastante apontado nas entrevistas diz respeito à língua, ao modo de falar e ao uso de expressões específicas do Nordeste. Muitas expressões, frases e adjetivos foram incorporados de alguma forma por muitas pessoas da cidade, especialmente os que convivem mais próximos dos "nordestinos".

Também é possível observar que os movimentos migratórios ocorreram em virtude da migração familiar, ou seja, famílias saíram da região Nordeste para se estabelecer em Anastácio. Este fato facilitou a adaptação no município e os levou a sentirem-se bem aceitos na cidade. A família aqui apresentada não se trata somente dos pais e filhos; mas corresponde à família expandida, ou seja, todos os membros - avós, tios e primos.

Conceitos relacionados às redes sociais constituem uma das formas de análise utilizadas para a compreensão de aspectos encontrados na organização espacial das sociedades atuais e da forma como estes aspectos são articulados ao território; dessa forma, as redes urbanas são importantes fornecedores de subsídios para este estudo, "já que o conjunto das articulações pode indicar quais subespaços dotados de um maior número de conexões capazes de gerar economias de aglomeração suficientemente fortes para atrais fatores de desenvolvimento" (MATOS; BRAGA, 2004, s.p.).

As redes sociais podem ser compreendidas de diferentes aspectos, pois são utilizadas como forma de análise para diversos casos. Uma das perspectivas é apresentada 
por Castells (2000), onde o autor afirma que as redes sociais globais atuam como fatores que "conectam e desconectam indivíduos, grupos, regiões e até países, de acordo com sua pertinência na realização dos objetivos processados na rede, em um fluxo continuo de decisões estratégicas" (p. 23). Um dos aspectos explicados através das redes sociais é a migração, que está diretamente relacionada ao processo de urbanização, uma vez que muitas migrações são motivadas pela busca de melhores condições de vida.

A partir desta abordagem, os deslocamentos populacionais são a expressão das possibilidades geradas a partir de um conjunto de relações nas quais o indivíduo se insere (SOARES, 2002). Dessa forma, as redes sociais não são geradas no movimento migratório em si, mas sim, transformadas pelos deslocamentos populacionais, na medida em que se reforçam as conexões que se estabelecem entre os migrantes e a sociedade local (SCHERER-WARREN, 2003).

Como reflexo do período de inserção dos migrantes no município e a forma como foram recebidos na cidade observa-se, através das declarações, que os migrantes gostam de Anastácio devido, principalmente, ao sossego e à tranqüilidade do município e do povo amistoso que encontraram na região. Uma característica que também é observada nas entrevistas, que pode ser considerada a mais relevante, é o fato de que os migrantes entrevistados afirmaram que o município apresenta um "ambiente nordestino", fazendo referência à sua região de origem.

\subsection{Festa da Farinha como expressão da cultura nordestina}

Parte significativa das interações que se estabelecem entre a cidade e o campo nos municípios brasileiros ocorre segundo uma lógica local. No município de Anastácio o processo estabelecido entre as áreas urbana e rural é fortemente influenciado pelo evento da Festa da Farinha de Anastácio, realizado desde 2006. O evento foi criado com o objetivo de promover o desenvolvimento e gerar renda para o município e os produtores de mandioca locais. Pode-se observar que houve um crescimento significativo da venda de farinha de mandioca artesanal proveniente dos assentamentos rurais do município e entorno, dos produtores que vendem e expõem seus produtos na festa, ao longo dos anos de realização do evento.

A festa acontece uma vez por ano no município, sua data de realização coincide com a semana de comemorações do aniversário da cidade, cuja temática principal está voltada para os produtos oriundos da mandioca ou que tenham algum subproduto(s) da mandioca em sua composição. No evento participam os moradores da área rural, em especial da Colônia Pulador, por estar concentrada neste assentamento a maior parte dos produtores de farinha de mandioca do município e também por ser a colônia que concentra o maior número de migrantes ou descendentes nordestinos.

A Festa da Farinha é considerada como a maior expressão da presença cultural nordestina no município e, muitas vezes, ela é citada como sendo a representação cultural nordestina em Anastácio, tanto pelos migrantes como pelos não-migrantes. A maior parte dos entrevistados disseram conhecer e participar do evento em todas as suas edições, sem especificar se na condição de público espectador ou de expositor ou outras funções. Grande parte dos entrevistados, migrantes ou não, acredita que a Festa da Farinha representa as características nordestinas, tão presentes na sociedade anastaciana. 
É interessante constatar que os entrevistados não-migrantes apresentaram uma maior variedade de respostas quanto às representações nordestinas na Festa da Farinha, ultrapassando o cunho gastronômico do evento (Gráfico 02). Eles apontam também questões culturais e seus aspectos peculiares - músicas, tradições, apresentações folclóricas, vestimentas, a Literatura de Cordel, entre outras. Já os migrantes nordestinos afirmam ser mesmo a gastronomia a maior representação da cultura nordestina.

\section{Gráfico 02}

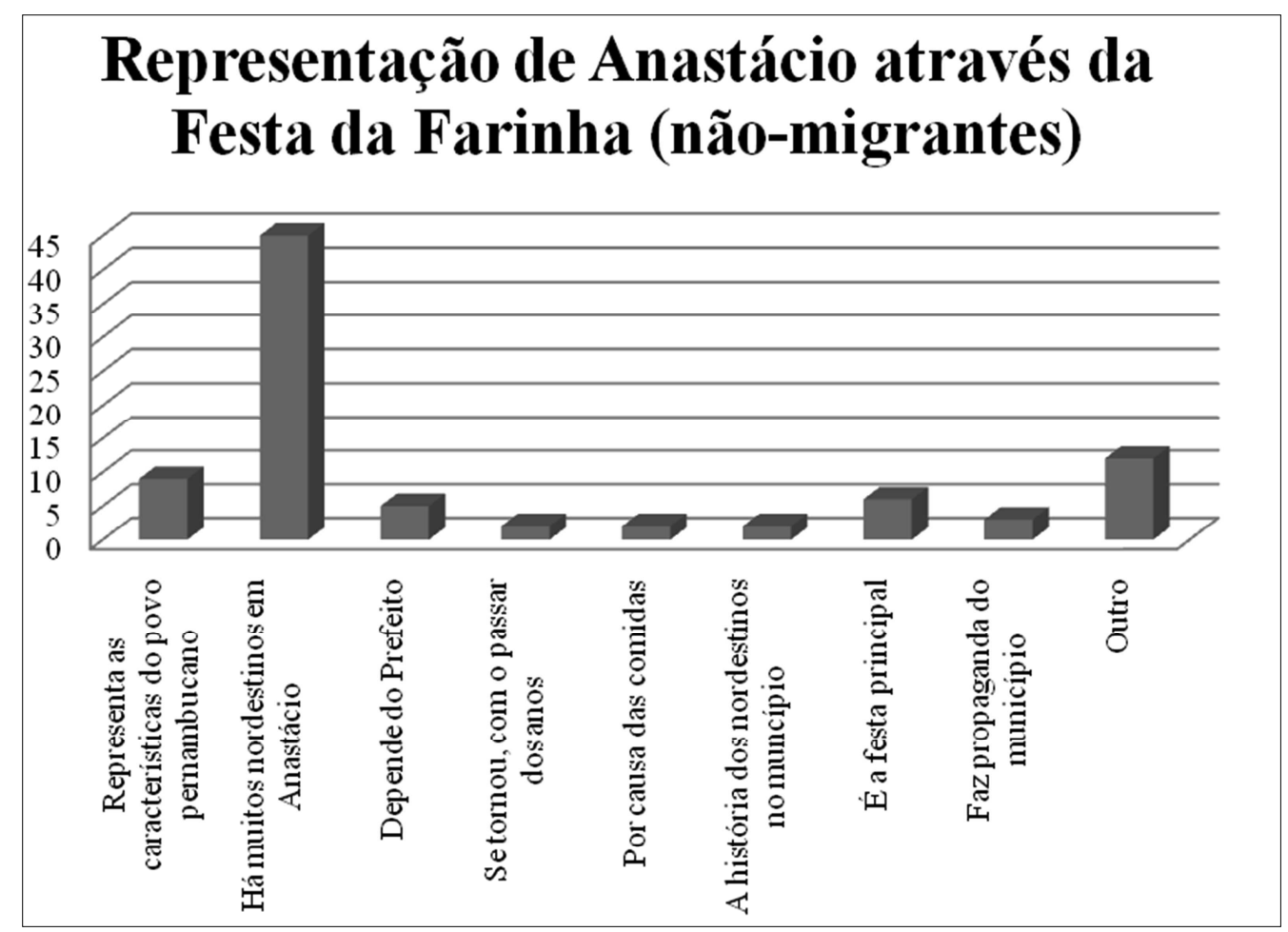

Fonte: Pesquisa de campo, 2009.

ORG.: TREVIZAN, 2010.

A identidade cultural é um processo oscilatório entre dois movimentos, daqueles que pretendem estabilizar e fixar as demais identidades presentes em uma mesma localidade, tal como aqueles que pretendem subvertê-la a fim de promover sua desestabilização (SILVA, 2000). Partindo dessa premissa, nota-se que a construção da identidade cultural de uma localidade configura-se como um processo que, muitas vezes, pode ser considerado arbitrário.

Essa ideia pôde ser observada durante as entrevistas com relação à representa- tividade da cidade através da Festa da Farinha, uma vez que alguns dos entrevistados afirmam que a festa só ocorre em virtude da descendência do administrador municipal, que tem suas raízes no povo pernambucano que migrou para a região. Todavia, pode ser observado na cidade e nas entrevistas, que muitos nordestinos e pessoas que não são descendentes, acreditam que as influências culturais nordestinas estão presentes na localidade e que elas representam Anastácio. Tal movimento pode ser caracterizado pela criação do 
Centro de Tradições Nordestinas de Anastácio, onde os sócios fundadores não são apenas os descendentes e migrantes, mas também pessoas que, de alguma forma, querem manter alguma ligação com a cultura nordestina.

Em função do evento ser considerado a maior representação cultural no município e, também, por causa da grande presença de nordestinos e descendentes na localidade, muitos entrevistados afirmaram que a festa é tida como uma representação da cidade de Anastácio (82,7\% - não-migrantes; 72,7\% - migrantes). Esse índice percentual alto nas respostas indica que a população de Anastácio reconhece que a cultura nordestina se sobressaia a ponto de determinar a organização e funcionamento contínuo daquela que é a maior e mais importante festa popular da cidade. Neste sentido são ressaltadas a "história dos nordestinos no município" e o que "representa as características do povo pernambucano", caracterizando-o assim, como uma representação do município e as influências que estes exercem sobre o local, desde os aspectos culturais abrangendo também questões sociais e até mesmo políticas (Gráficos 02 e 03).

Gráfico 03

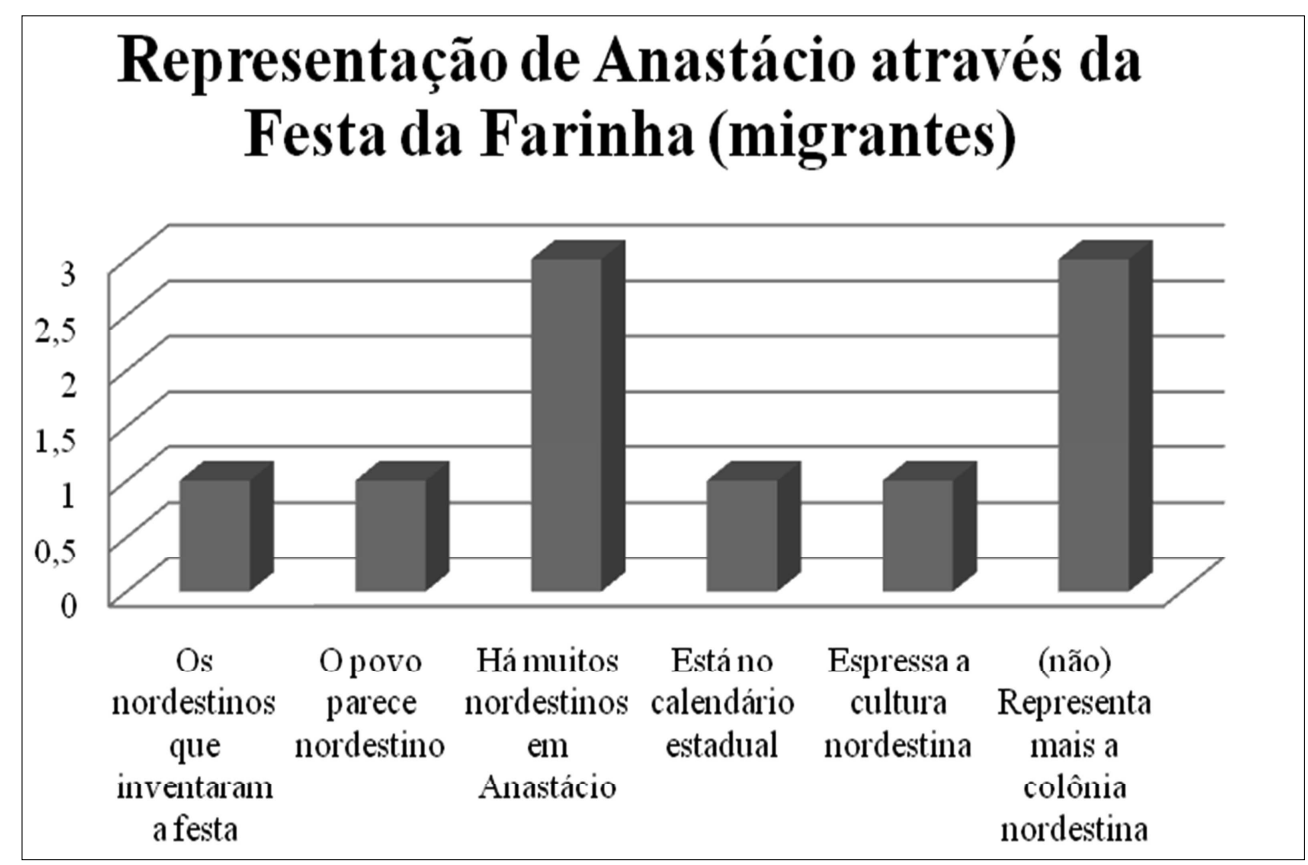

Fonte: Pesquisa de campo, 2009.

Org.: TREVIZAN, 2010.

No Gráfico 03, a última barra demonstra a parcela dos entrevistados migrantes que não acreditam que a Festa da Farinha represente o município de Anastácio, considerando que o evento "representa mais a colônia nordestina" do que ao município. Entre os entrevistados não-migrantes, a ideia de que o evento representa mais a colônia nordestina do que ao município também é compartilhada por alguns dos entrevistados, pois, de acordo com eles, o município conta com "várias outras culturas", e, trata-se de uma localidade pantaneira e não nordestina. A festa apresenta 
somente uma das manifestações culturais no município (Gráfico 04). Dentre as demais manifestações das culturas presentes no município que foram citadas durante as entrevistas foram: a Festa da Padroeira, os rodeios, a Festa do Peão, o Arraiá de Santo Antonio, entre outras.

\section{Gráfico 04}

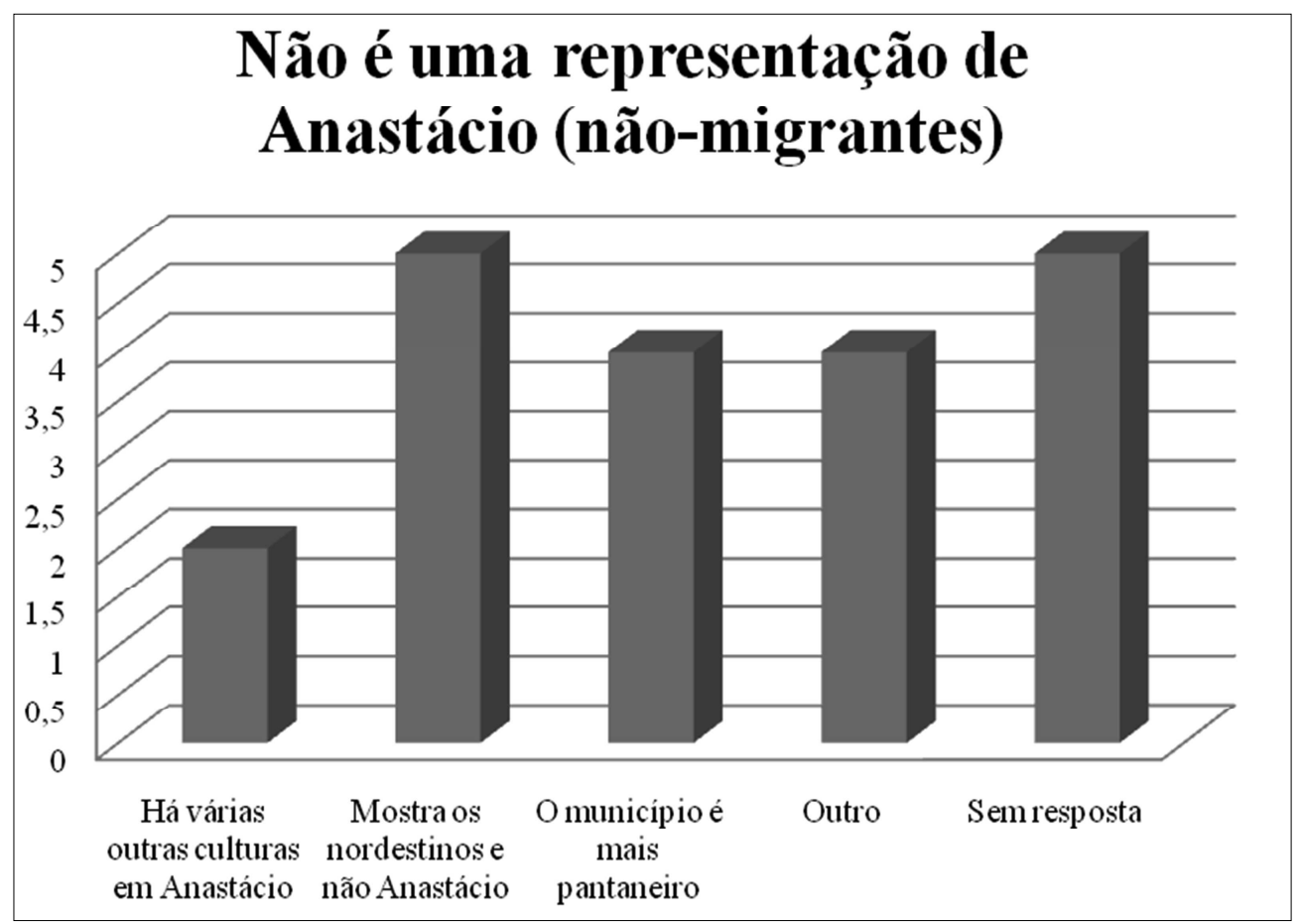

Fonte: Pesquisa de campo, 2009.

Org.: TREVIZAN, 2010.

\section{CONSIDERAÇÕES FINAIS}

O município de Anastácio conta com diferentes influências culturais, provenientes das diferentes regiões do Brasil e de países ao redor do mundo, no entanto, apresenta em sua constituição populacional um grande número de migrantes nordestinos, que correspondem à maior manifestação cultural da atualidade no local. O município também conta com outras manifestações das demais culturas presentes na localidade, no entanto, sem muita expressão, se comparadas com a Festa da Farinha de Anastácio, que faz referência às influências dos migrantes pernambucanos, que são maioria entre os migrantes nordestinos.
Os movimentos migratórios aconteceram em grupos familiares diretamente para a região que atualmente é o município de Anastácio. Estes se deslocavam por variadas razões, entre elas a busca por uma vida melhor, por ser uma região "nova" ou por algum parente ou conhecido que já havia se estabelecido na região ter afirmado que ali "estava bem". No entanto, há migrantes que saíram do Nordeste para outras regiões, que não a de Anastácio, e que, posteriormente, se mudaram para Anastácio, permanecendo ali. Em grande parte dos casos, os migrantes se estabeleceram nas colônias presentes na área rural do município, onde ainda residem trabalhando com o cultivo de alimentos de subsistência e com a criação de animais. 
Durante as entrevistas, a cultura caracterizou-se como uma forma de adaptação e transformação (CERTEAU, 1995) que os migrantes nordestinos inseriram ao se fixarem em Anastácio, uma vez que suas características culturais constituem e tornaram-se uma das principais expressões da cultura anastaciana, sendo aceita tanto pela população diretamente ligada aos migrantes (próprios migrantes e descendentes) como também pela população não diretamente ligada aos migrantes (anastacianos e migrantes ou descendentes de outras regiões).

As redes sociais são essencialmente 0 meio pelo qual os sistemas migratórios ocorrem. As análises dos movimentos migratórios devem considerar o migrante não somente por seus atributos pessoais ou intenções individuais, mas sim como uma entidade dotada de relações que se conecta a outros conjuntos compostos por laços de parentesco, amizade, conhecimento, trabalho, entre outros.

\section{REFERENNCIAS}

BARBOSA, J. Entrevista concedida a F. Trevizan. 2009.

CABRAL, S. et al. Anastácio 38 anos. Campo Grande-MS: Gráfica e Editora Alvorada, 2003.

CASTELLS, Ml. O Poder da Identidade. São Paulo: Paz e Terra, 2000.

CERTEAU, M. de. A Cultura no Plural. São Paulo: Papirus, 1995.

CUCHE, D. A Noção de Cultura nas Ciências Sociais. Bauru-SP: Edusc, 2002.

HAESBAERT, R. O Mito da Desterritorialização: Do Fim dos Territórios à Multiterritorialidade. Rio de Janeiro: Bertrand Brasil, 2004.

IBGE. Anastácio (MS): Produto Interno Bruto. 2007. Disponível em: http://www.ibge.gov.br/ cidadesat/painel/painel.php? codmun=500070\# Acessado em: 07 nov. 2009.
Anastácio (MS): Perfil da População. 2008. Disponível em: http://www.ibge.gov.br/cidadesat/painel/painel.php?codmun=500070. Acessado em: 06 nov. 2009).

LANZARINI, R. Projeto: II Festa da Farinha de Anastácio - MS. Anastácio - MS, 2007.

MATOS, R.; BRAGA, F. Redes sociais, redes territoriais e migração. In: Anais do XIV Encontro Nacional de Estudos Populacionais - ABEP. Caxambú/MG. 2004.

OLIVEIRA, L. M. B. de. Identidade Cultural. Disponível em: http:/ / www.esmpu.gov.br/dicionario/tiki-index.php?page $=$ Identidade + cultural Acessado em: 14 out. 2008.

PÓRTICO da II Festa da Farinha de Anastácio - MS. Jornal O Pantaneiro, 2007.

ROCHA, A. R. P. e MONASTIRSKY, L. B. A dialética entre o global e o local: um olhar sobre o turismo e o patrimônio cultural. Revista Terr@Plural, Ponta Grossa, v. 2, n.1: 145-154, jan./jun., 2008.

S/A. Anastácio. Disponível em: http:// pt.wikipedia.org/wiki/Anast\%C3\%A1cio_(Mato_ Grosso_do_Sul). (acesso em: 18 de julho de 2009).

SANTOS, M. Da Totalidade ao Lugar. São Paulo: Edusp, 2005.

SCHERER-WARREN, I. Sujeitos e movimentos conectando-se através de redes. Política e Trabalho. n. 19, Outubro, 2003. Disponível em: http:/ / cchla.ufpb.br/politicaetrabalho/arquivos/artigo_ed_19/artigos/artigo_02.pdf. Acessado em: 28 set. 2009 .

SILVA, S. G. et al. Análise Institucional e Qualidade de Vida. In: GABRIEL, M. L. A. et al. (Orgs). Revista ECETUR - Encontro Cientifico de Estudantes de Turismo. Três Lagoas - MS: AEMS, 2005/2006.

SILVA, T. T. A Produção Social da Identidade e da Diferença. In: SILVA, T. T. Identidade e Diferença: a perspectiva dos estados culturais. Petrópolis - RJ: Vozes, 2000.

SOARES, W. Da metáfora a substância: redes sociais, redes migratórias e migração nacional e internacional em Valadares e Ipatinga. Belo Horizonte/MG: CEDEPLAR/UFMG, 2002.

SODRÉ, N. W. Síntese da História da Cultura Brasileira. Rio de Janeiro: Civilização Brasileira, 1996.

TREVIZAN, F. K. F. III Festa da Farinha de Anastácio-MS: Cultura, Gastronomia e Turismo - Um 
Fernanda Kiyome Fatori Trevizan; Leonel Brizolla Monastirsky

Estudo de Caso. Aquidauana - MS: UFMS, 2008.

(monografia de conclusão de curso - Turismo).

WOODWARD, K. Identidade e diferença: uma introdução teórica e conceitual. In: SILVA, T. T. Identidade e diferença: a perspectiva dos estados culturais. Petrópolis-RJ: Vozes, 2000.

Recebido em: 24/12/11

Aceito em: 03/03/11 